Earth \& Environment | Sheffield Water Research Group

\section{Water in Crisis}

Delivering urban and natural water cycle symbiosis

The Water Research Group and Structural Enginering

the University of Sheffield is

the UK's largest urban water

research team. Their research

encompasses the entire wate

assessing the environming

assessing the environmental

groundwater and rivers,

stormwater management and

flooding, green and urban water

infrastructure engineering, and

management of buried assets

to optimise performance and

safeguard drinking wate

quality. Their pioneering

recognised and aims to

continue delivering sustainable

engineering solutions that

promote active urban and

natural water cycle symbiosis. ater is in crisis. The Water
Research Group in the
Department of Civil and international researchers to deliver trans of Sheffield is at the forefront of pioneering innovative solutions. Water is a fundamental need of life and critica to society, global economies and the a tap, we see a clean and we turn on of water that we take for granted. We rarely consider how it got there, how our wastewater is removed or how integral this urban water cycle is to our everyday lives and well-being.

Covid-19 has brought public health concerns to the forefront, but viruses exist everywhere, even in our drinking water. This should not be a cause of fear, but is an example of something we must embrace and work with in harmony to ensure resilience in the quantity and provides essential research and services facilitating this synergy.

The Sheffield Water Research Group is the UK's largest urban water research entire water senvice provision insluding assessing the environmental impact and protection of groundwater and rivers, stormwater management and and safeguard drinking water quality. Their research spans fundamental aspects to application, with a focus on challenge-driven issues. They work with water utilities, consultants, contractors and other stakeholders internationally and advise governments and policy-makers. In addition to Civir and Structural Water Engineering,
they collaborate across the University

\section{BIOFILMS IN DRINKING WATER} public health through the provision of complies with prescribed standards. on its journey through the immense, yet hidden world of drinking water pipe walls, which are governed by the complex microbial biofilms that within aquatic environments as it is not resolving worldwide problems and quality of our water. The Water Resea Group at the University of Sheffield flooding, green and urban infrastructure engineering, and management of buried assets to optimise performance

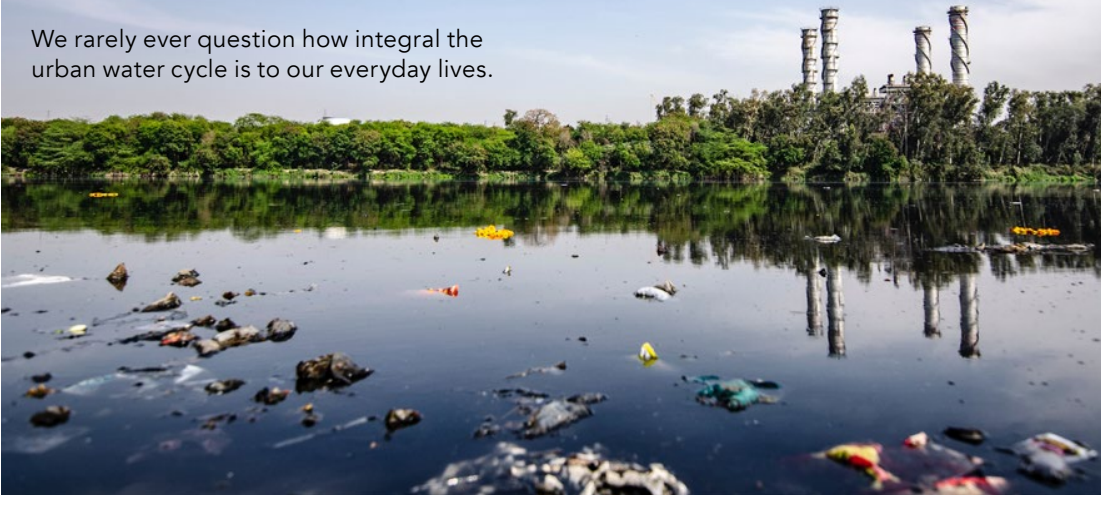

possible to create sterile conditions. In act, natural biofilms provide essential safety features resisting pathogens, yet unmanaged they can lead to aesthetic and health issues. Researchers at Sheffield are developing techniques to investigate these ecosystems and the including bacteria, viruses and fungi and . This understanding is promoting better pro-active management, ensuring beneficial community colonisation and safe adaptation to issues such as climate change or changing water sources required to tackle increasing worldwide water scarcity.

\section{WATER DISTRIBUTION SYSTEMS} AND INFRASTRUCTURE Safeguarding water quality in order to protect public health underpins our water supply systems. Satisfying customers' expectations while managing ageing and deteriorating distribution ystems, however, presents challenges comple unt resting to drinking quality concerns discoloured water appearing from consumers' taps: Researchers working on the Prediction of Discolouration in Distribution Systems (umw PODDS CO uk project explain, with the aid of in-house developed modelling tools, how the accumulation of organic and non-organic material on pipe walls can cause discolouration and other issues such as taste and odour problems.

The PODDS team explore how hydraulic conditions in our drinking water distribution systems can both impact, and be used to manage, this risk. Results material concentrations in transmitted water accumulate on pipe walls in show how the low-level background creating an inevitable and endemic discolouration risk. By understanding the hydraulic characteristics, however, significant cost savings can be made over traditional cleaning methods 政 engineered ecosystem. One strategy flow monitoring to safely remove excess material without disupting the natural biofims, leading to cleaner systems with improved resilience. Along with real-time network monitoring water quality samples are routinely collected but the resulting data has typically

Covid-19 has brought public health concerns to the forefront, but viruses exist everywhere, even in our drinking water.

been archived rather than analysed. approaches to analyse historical water quality databases to identify dominant discolouration risk, such as nitrification and cast iron mains. This approach is being used to inform interventions and justify investments to help safeguard drinking water quality.

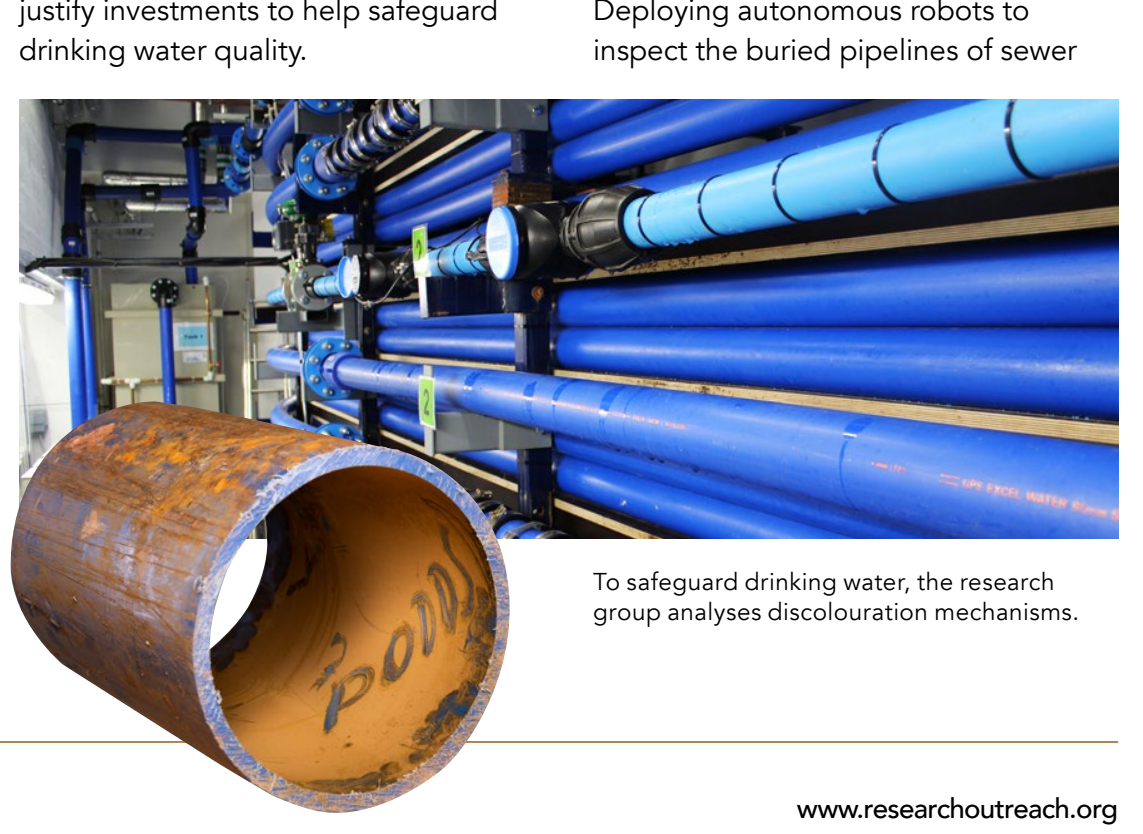
of disruptive one of the eight themes researchers at Sheffield are taking a nexus as they integrate renewable the distribution of drinking water and wastewater collection. Simulations have combined the energy produced by heat recovered from the sewer network with wind turbines and solar photovoltaic panels. Results reveal that such an demand for up to $63 \%$ of the time over demand for up to $63 \%$ of the time over carbon emissions could be reduced by $55 \%$ and the associated $\mathrm{CO}_{2}$ reduced by $60 \%$ compared to heating with natur neighbourhoods could help governments meet carbon emission obligations.

PIPEBOTS Researchers are using machine learning
TWENTY65: A NEW TAKE ON

The Sheffield Water Research Group leads the EPSRC-funded Grand Challenge consortium TWENTY65 to the future of water supply. Interdisciplinary teams are researching and developing innovative long term synergistic and sustainable ways of a positive impact on our health, the environment, economy and society. As novel approach to the energy-water distribution systems. Central to this integrated system could satisfy the heat 


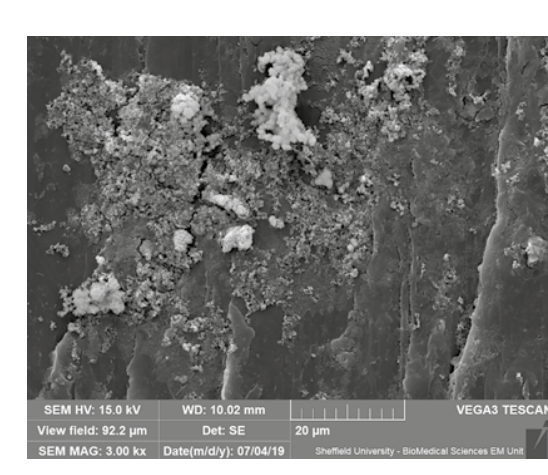

Natural biofilms in water pipes provide ess potential to provide effective nondestructive methods for examining internal pipe structure and identifica of performance issues. The Water Research Group at Sheffield are leading the EPSRC-funded Pipebots project (www.pipebots.ac.uk) in partnership with researchers from three other UKansform the capabilties of aims to moving them towards failure free operation and preventing unplanned road excavation by developing pipescale robots. These Pipebots need to be capable of inspecting and working inaccessible pipes,
which incorporates a range of challenges, such as high pressu and potentially explosive gases. Simulations using biologically inspired behaviour, which take into
account network length, topology, the account network length, topology, the highlight the potential to monitor entire networks.

Robotic sensing enables Pipebots to extract accurate and relevant information concerning the condition of pipes together with location and fault diagnosis in real time with minimal human interaction. Artificial Intelligence (Al) and machine learning techniques are being used to refine performance and given the energy contained in moving fluids, energy-harvesting hardware is also being developed. The Pipebots team have the advantage of being able to use the facilities at the National Distributed Water Infrastruct Facility at ICAIR (the Integrated Civi and Infrastructure Research Centre,
www.icair.ac.uk) to develop and perfo
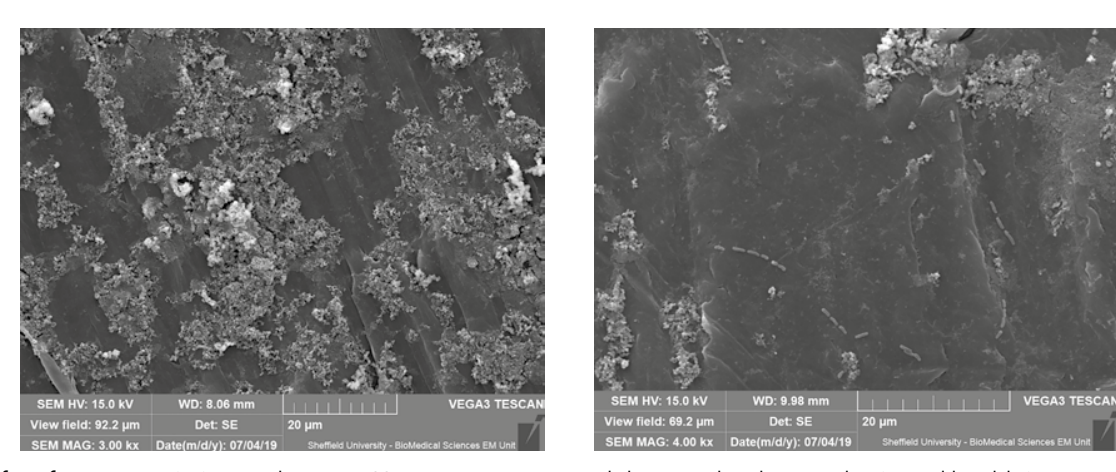

controlled testing of the robots at full scale before moving onto field testing.

\section{PROTECTING}

GROUNDWATER QUALITY

Since 2000, research funded by EPSRC, the Environment Agency and private investigatio fact tated long-term of gasoline ether oxygendes (GEO) that pollute European groundwates. The research has advanced

fundamental understanding of microbial transformation of these petroleum additives (used to improve combustion and reduce vehicle emissions), with

flood modelling approaches developed at the Sheffield Water Research Group that can be used to estimate the impact of flooding on building damage, potential loss of life, and highlight countermeasures to ensure safety.

The EPSRC-funded Urban Green DaMS project takes a different, but flood risk by conducting research to enhance the understanding of the

performance of bioretention cells. These are sustainable drainage systems that retain and detain rainwater before it enters drainage networks while also

delivering a positive delivering a positive
impact on water Researchers are developing pipe-scale impact on wate bots that are capable of inspecting and and biodversty working in underground pipe networks knowledge of these vices allows be developed $\begin{array}{ll}\text { innovative monitoring strategies and } & \text { to give drainage engineers confidence } \\ \text { restoration concepts developed that } & \text { in performance allowing them to be }\end{array}$ restoration concepts developed that the environmental risk posed by GEOS in groundwater.

\section{URBAN FLOODING}

The recently completed $\mathrm{H} 2020$ funded CENTAUR project developed an innovative and cost-effective local autonomous sewer flow control system to reduce urban flood risk. The CENAUR system uses control gates opedware to local Al-based control parts of the catchment to reduce flood risk at downstream locations. It is now being exploited by commercial partn to allow existing infrastructure to be better utilised, either reducing the ne for large capital schemes, or buying dime before such schemes can be in performance allowing them to
incorporated in urban planning.

\section{URBAN WATER AND NATURAL}

\section{WATER CYCLE SYMBIOSIS}

Engineered systems that protect

continuous clean water and remove

wastewater are complex and ageing

with operation and management

incurring significant energy, chemical

and capital costs. The Water Research Group at Sheffield is delivering

sustainable solutions to reduce these

costs while fulfilling industry needs

and improving the urban water example innovations highlighted here give a flavour of how their work is using a symbiosis between the natural water delivery of these eyses to optimise infrastructure and environment. The

\section{Behind the Research}

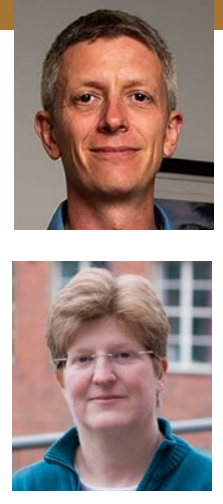

\section{Prof Joby}

Boxal

E: i.b.boxall@sheffield

Prof Virginia

Stovin

E: v.stovin@sheffield

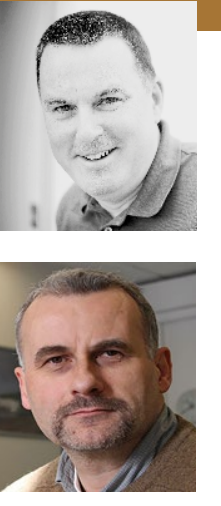

Prof lan

Guymer

E: i.guymer@sheffield

Prof Steve

Thornton

E: s.f.thorntone

heffield.ac.uk

W: https://www.sheffield.ac.uk/civil/water (a) Dr Georges

Kesserwani

E: g.kesserwani@

seffield.ac.uk

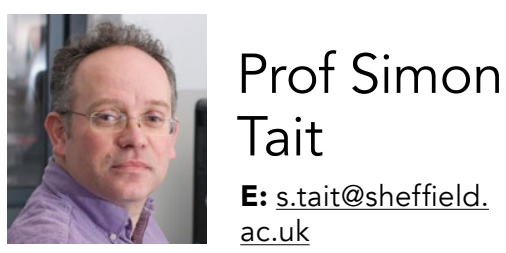

E: s.tat

s.tait@sheffield.
References

- Liu, F., Tait, S., Schellart, A., Mayfield, M., and Boxall, J. (2020). and renewable energy sources at a community scale. Renewable and Sustainable Energy Reviews, Ionline] 123, 109767. Available af: - Thtps://doi.org, No.1016/1.rser.2020.10976

Spence, M.J. (2020). Biodegradation and fate of ethyl tert-

butyl ther (ETBE) in soil and groundwater: a review. Journal
of Hazardous Materials, 391, 122046. Available at: https://doi.

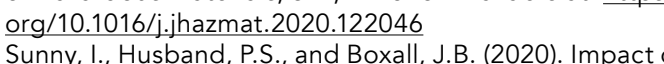

hydraulic interventions on chronic and acute material loading and discolouration risk in drinking water distribution systems. Ionlin org/10.1016/j; watres.2019.115224

- Douterelo, I., Dutili, B.E., Arkhipova, K., Calero, C., and Husband, S. (2020). Microbial diversty, ecological networks and function a systems. Water Research. Available at: https://doi.org/10.101016/i

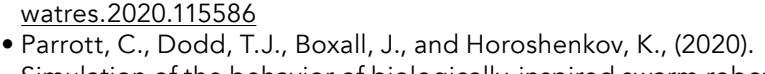
Simulation of the behavior of biologically-inspired swarm robots for the autonomous inspection of buried pipes. Tunnelling and
Underground Space Technology, [online] 101, 2020, 103356 . Available at: https:///doi.org/10.1016/i.tust.2020.103356

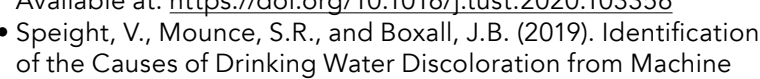
of the Causes of Drinking Water Discolor ation from Machine Water Research \& Technology, 5, 747-755. Available at: https://do orge/10.1039/C8EWO0733K
De-Ville, S.M Menon, M. and Stovin, V. (2018). Temporal variations in the potential hydrological performance of extensive green
roof systems, Journal of Hydrology, 558, 564-578. Available at: hottps://doi.iorg/10.1016/jijhydrol.2018.01.055
Abdel-Aal, M. Schellart, A. Kroll, S., Mohamed, M., and Tait, S. - Abdel-Aal, M., Schellart, A., Kroll, S., Mohamed, M., and Tait, S.
(2018). Modelling the potential for multi-location in-sewer heat recovery at a city scale under different seas Research, 145, 618-630. Available at: https://doi.org/10.1016/1 watres.2018.08.073 structures (EPS and bacterial communities) in drinking water
string

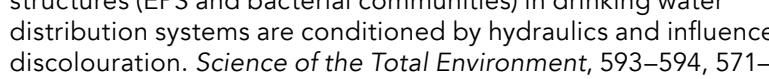
discolouration. Science of the Total Environment, 593-594, 571-
580. Available at: https://doi.org/10.1016/j.scitotenv.2017.03.176 - (2017). Transverse and lonestudinal mixing in real emergent vegetation at low velocities. Water Resources Research, 53(1), $961-$
978. Available at: https://www.doi.org/10.1002/2016WR019937
Research Objectives

The Water Research Group at the University of Sheffield aims to tural water cycle symbiosis.

Detail

Bio
Joby Boxall is Professor of Water Infrastructure Engineering
at the University of Sheffield, and Head of Department of Civil at the University of Sheffield,
and Structural Engineering.

lan Guymer is an EPSRC Established Career Research Fellow. Georges Kesserwani is an Environmental Change Fellow
holding an EPSRC Fellowship.

Virginia Stovin is Professor of Green Infrastructure for
Stormwater Management.

Steve Thornton is Professor of Environmental Engineering

Simon Tait is Professor of Water Engineering and Urban Water
Infrastructure Systems.

Funding
UKRl in general, EPSRC specifically and critically our longstanding grusted collaborative partherships across the
water sector.

Personal Response What has been the most rewarding outcome of the
Water Research Group's work?

II Stewart Husband: It is truly exciting and rewarding
to know that by respecting and working with the natural water cycle we are able to deliver pioneering engineering
solutions that supports society and helps protect the entire planet. Water is fundamental to life, so investigatin and working in harmony with this essential resource for
everyone's benefit is a privilege.

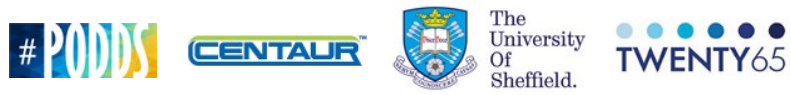

